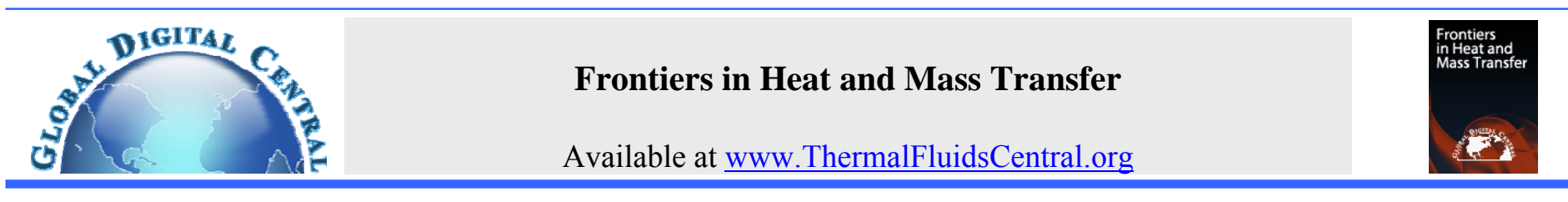

\title{
CHEMICALLY REACTIVE VISCOELASTIC FLUID FLOW IN PRESENCE OF NANO PARTICLE THROUGH POROUS STRETCHING SHEET
}

\author{
S. M. Arifuzzaman ${ }^{1}$, Md. Shakhaoath $\mathrm{Khan}^{2}$, Khan Enaet Hossain ${ }^{1}$, Md. Sirajul Islam ${ }^{3}$, Sonia Akter ${ }^{3}$ and Raju Roy ${ }^{1}$ \\ ${ }^{\prime}$ Mathematics Discipline, Khulna University, Khulna, 9208, Bangladesh \\ ${ }^{2}$ Discipline of Chemical Engineering, University of Newcastle, Callaghan, NSW 2308, Australia \\ ${ }^{3}$ Department of Mathematics, Bangabandhu Sheikh Mujibur Rahman Science and Technology University, Gopalganj, 8100, Bangladesh
}

\begin{abstract}
Present study concerned with the theoretical work with numerical investigation of MHD transient naturally convective and higher order chemically reactive viscoelastic fluid with nano-particle flow through a vertical porous stretching sheet with the effects of heat generation and radiation absorption. A boundary layer approximation is carried out to develop a flow model representing time dependent momentum, energy, and concentration equations. The governing model equations in partial differential equations (PDEs) form were transformed into a set of nonlinear ordinary differential equation (ODEs) by using non-similar technique. Explicit Finite Difference Method (EFDM) was employed by implementing an algorithm in Compaq Visual Fortran 6.6a to solve the obtained set of nonlinear coupled ODEs. For optimizing the system parameter and accuracy of the system, the stability and convergence analysis (SCA) was carried out. It was observed that with initial boundary conditions, for $\Delta \tau=0.005$, $\Delta X=0.20$ and $\Delta Y=0.25$, the system converged at Prandtl number, $P_{r} \geq 0.253$ and Lewis number, $L_{e} \geq 0.16$. The velocity, temperature and concentration flow are investigated and shown graphically with the effect of system parameters and numerical comparison.

Keywords: Viscoelastic Fluid, Nano Particle, Radiation Absorption, High Order Chemical Reaction, Heat and Mass Transfer.
\end{abstract}

\section{INTRODUCTION}

In the last few decades, the magnetohydrodynamic (MHD) heat and mass transfer flow leads a broad significant importance in fluid flow engineering technology industries. The laminar fluid flow which results from the stretching of a flat surface in a nanofluid has been investigated numerically by Khan et al. (2010) and Noghrehabadi et al. (2012), which was to analyze the development of the steady boundary layer flow, heat transfer and nano-particle fraction over a stretching surface in a nanofluid. The viscoelastic nanofluid flow and heat transfer over a linearly stretching sheet in the presence of externally applied magnetic field. The effects of Brownian motion and thermophoretic volume fraction of nano-particles have been investigated by Shit et al. (2016). The problem is solved numerically by using finite difference scheme along with the Newton's linearization technique. A wide range of applications can be found in several fields such as aerodynamic extrusion of plastic sheets, energy storage units, biological transportation, liquid metal fluids oil reservoirs, high-temperature plasmas, geothermal systems, heat insulation and metal and polymer extrusion, thermal energy storage devices, electronic cooling, boilers, nuclear process, micro MHD pumps, ground water systems etc. Investigations of MHD flows are mostly in vertical moving porous plate Mohamed et al. (2009), vertical porous plate Nandy et al. (2013) and Murthy et al. (2015), vertical insulated porous plate, infinite inclined porous plate Ramachandra et al. (2011), semi-infinite vertical porous plate Das et al. (2015). In recent days, nanotechnology has received a lot of attention where the further development of higher performance is still going due to effective applications in the field of cooling (transformer cooling, electronics device cooling, silicon mirror cooling, vehicles cooling, controlling fusion), biomedical (magnetic cell separation, drug delivery, cancer therapeutics, cryopreservation, nano cryosurgery) etc. The term "nano fluid" can be refers to a class of fluids by suspending nanometre sized (1-100 nm diameters) particles in common base fluids of highly enhanced thermal properties (Ferdows et al., 2013; Dogonchi et al., 2016). This type of fluids has highly industrial importance because of its unique chemical and physical properties. It has a higher thermal conductivity which controlled significant enhancement due to the rate of heat transfer.

Viscoelastic fluid model is one of the subclass of rate type fluids which has gained wide attractions among the researchers in last 10 years. The fluid of both viscosity and elasticity properties is so called viscoelastic fluid. The main advantage of using this kind of fluids is it can predict the stress relaxation whilst other differential-type fluids cannot predict such effects. Maxwell fluid widely used in the field of viscoelastic fluid in where the relaxation time (dimensionless) is insignificant however, it's beneficial for significant relaxation time in concentrated polymeric fluids of low molecular weight Ibáñez et al. (2016) and Fetecau et al. (2003). Khan et al. investigated MHD heat and mass transfer axisymmetric chemically reactive Maxwell fluid flow of driven by exothermal and isothermal stretching disks. In the presence of nano particles, Ramesh et al. (2016) studied Maxwell fluid stagnation point flow of near a permeable surface. Recently, the radiation and viscous dissipation effects on Maxwell fluid flow in a

"Corresponding author. Email: arifsm42@gmail.com (SM Arifuzzaman); Md.S.Khan@newcastle.edu.au (MS Khan) 
combined MHD heat transfer thermal extrusion system was studied by Hsiao (2017).

Flow and heat transfer of MHD nanofluid between parallel plates in the presence of thermal radiation model has been analyzed analytically with Duan-Rach Approach (DRA) by Dogonchi et al. (2016). Biswas et al. (2017) investigated the effect of presence of magnetic field, thermal radiation, heat source, viscous dissipation on boundary layer unsteady mixed convective Jeffrey nanofluid flow over a vertical stretching sheet has remained unexplored. Therefore, it is thought desirable to investigate this problem in the present study. A well-known explicit finite difference method (EFDM) (Khan et al., 2012; Bég et al., 2014) employed as a numerical tool to solve the flow governing model. Dogonchi et al. (2017) investigated MHD Go-water nanofluid flow and heat transfer in a porous channel in the presence of thermal radiation effect with DRA method. This method modifies the standard A domian Decomposition Method by evaluating the inverse operators at the boundary conditions directly.

To the best of the author's knowledge, the study of natural convective and chemically reactive viscoelastic fluid flow with nanoparticle through a vertical porous stretching sheet in presence of thermal radiation, heat generation and radiation absorption has remained unexplored. Therefore, this phenomenon is addressed in this study. The specific objectives of this numerical investigation are listed below:

a) To investigate unsteady chemically reactive viscoelastic fluid flow with nano particle through a vertical porous stretching sheet with the influence of thermal radiation, mass diffusion with heat source, mass transfer and radiation absorption.

b) Mathematical solution of the flow governing model which includes transient momentum, energy and diffusion balance equations numerically using well-known explicit finite difference method (EFDM).

c) Optimizing the numerical flow parameters and predicting high accuracy of EFDM solutions by analysing stability and convergence analysis (SCA).

d) To study velocity, temperature, and concentration distribution across the boundary layer. Investigation on skin friction coefficient, Nusselt number and Sherwood number with different physical parameters.

e) Evaluation of the thermal and momentum boundary layer thickness with isotherms and streamlines analysis.

\section{FLUID FLOW MATHEMATICAL MODEL}

The fluid with the both viscosity and elasticity properties is known as viscoelastic fluid. Unsteady heat and mass transfer flow of viscoelastic fluid along a semi-infinite vertical porous plate $y=0$ is considered in the presence of a uniform thermal radiation and magnetic field. The flow is considered to be in the $x$-direction which is taken along the plate in the upward $x$-direction and $y$-axis is normal to it. When, the plate velocity $U(t)$ is given as $u=U_{0}$. In initial step, it is considered that the plate as well as the fluid particle is at rest at the same temperature $T\left(=T_{\infty}\right)$ and the same concentration level $C\left(=C_{\infty}\right)$ at all points.

Where, $C_{\infty}$ and $T_{\infty}$ are fluid concentration and temperature species of uniform flow respectively. It is also assumed that a magnetic field $B_{y}=B_{0}$ of uniform strength is applied normal to the flow region. The physical configuration and co-ordinate system of the problem is presented in the following Fig. 1. To the best of the author's knowledge, the study of natural convective and chemically reactive viscoelastic fluid flow with nano particle through a vertical porous plate in presence of thermal radiation, heat and radiation absorption has remained unexplored. Therefore, this phenomenon is addressed in this study. Under the above assumptions, the equations that described the physical circumstances are given below (Shit et al., 2016):

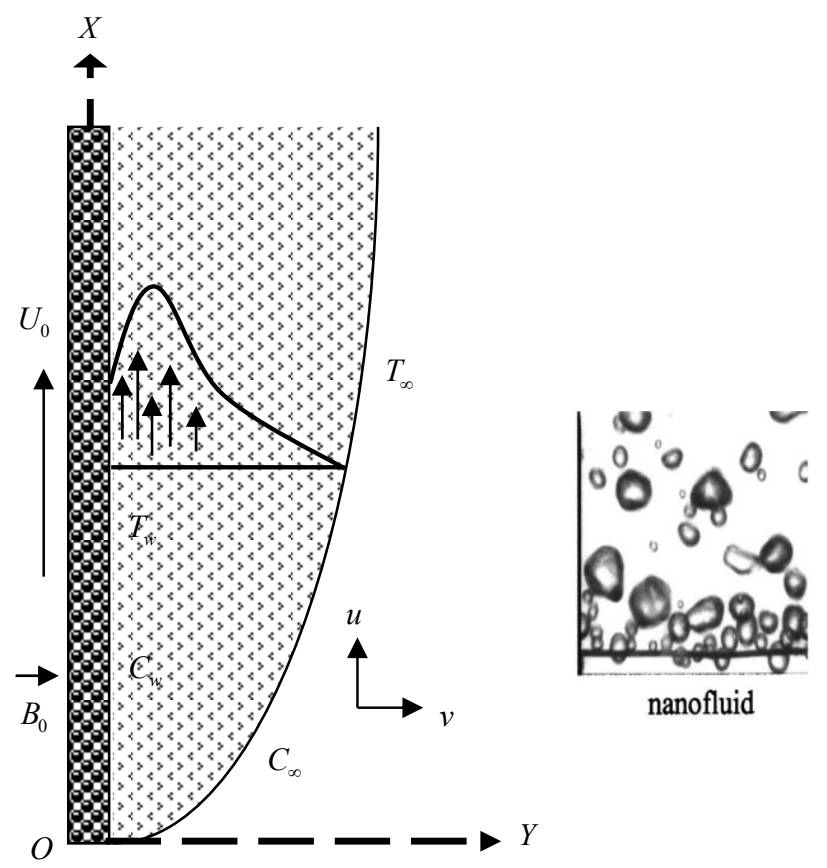

Fig. 1 Physical configuration and coordinate system

Continuity Equation

$\frac{\partial u}{\partial x}+\frac{\partial v}{\partial y}=0$

\section{Momentum Equation}

$\frac{\partial u}{\partial t}+u \frac{\partial u}{\partial x}+v \frac{\partial u}{\partial y}=v \frac{\partial^{2} u}{\partial x^{2}}-\frac{\lambda_{o}}{\rho}\left[\frac{\partial^{3} u}{\partial t \partial y^{2}}+u \frac{\partial^{3} u}{\partial x \partial y^{2}}+v \frac{\partial^{3} u}{\partial y^{3}}-\frac{\partial u}{\partial y} \frac{\partial^{2} u}{\partial x \partial y}\right.$

$\left.+\frac{\partial u}{\partial x} \frac{\partial^{2} u}{\partial y^{2}}\right]-\frac{\sigma B_{0}^{2}}{\rho} u+g \beta\left(T_{w}-T_{\infty}\right)+g \beta^{*}\left(C_{w}-C_{\infty}\right)-\frac{v}{k} u$

Energy Equation

$\frac{\partial T}{\partial t}+u \frac{\partial T}{\partial x}+v \frac{\partial T}{\partial y}=\frac{\kappa \partial^{2} T}{\rho c_{p} \partial y^{2}}+\frac{v}{c_{p}}\left(\frac{\partial u}{\partial y}\right)^{2}+\frac{Q_{0}}{\rho c_{p}}\left(T_{w}-T_{\infty}\right)$

$+\frac{Q_{1}^{*}}{\rho c_{p}}\left(C_{w}-C_{\infty}\right)-\frac{1}{\rho c_{p}} \frac{\partial q_{r}}{\partial y}+\frac{D_{m} \kappa_{T}}{c_{s} c_{p}} \frac{\partial^{2} C}{\partial y^{2}}+\frac{\sigma^{\prime} B_{0}^{2} u^{2}}{\rho c_{p}}$

$+\Gamma\left\{D_{B}\left(\frac{\partial T}{\partial y} \frac{\partial C}{\partial y}\right)+\frac{D_{T}}{T_{\infty}}\left(\frac{\partial T}{\partial y}\right)^{2}\right\}$

Concentration Equation

$\frac{\partial C}{\partial t}+u \frac{\partial C}{\partial x}+v \frac{\partial C}{\partial y}=D_{B}\left(\frac{\partial^{2} C}{\partial y^{2}}\right)+\frac{D_{T}}{T_{\infty}} \frac{\partial^{2} T}{\partial y^{2}}-K_{c}\left(C-C_{\infty}\right)^{P}$

With boundary condition,

$t=0, u=U_{0}=b x, v=0, T=T_{w}, C=C_{w}$ every where

$t \geq 0, u=0, v=0, T=T_{\infty}, C=C_{\infty} \quad$ at $\quad x=0$

$u=U_{0}=b x, v=0, T=T_{w}, C=C_{w}$ at $y=0$

$u=0, T \rightarrow T_{\infty}, C \rightarrow C_{\infty}$ at $y \rightarrow \infty$

Where, $u$ and $v$ are the velocity component, $B_{0}$ is the magnetic field component, $\beta$ is thermal expansion coefficient $\beta^{*}$ is concentration expansion coefficient, $T_{w}$ denotes the wall temperature, $C_{w}$ is the species concentration at the wall, $b$ is the stretching constant, $v$ is the kinematic viscosity, $\rho$ is density, $\lambda_{0}$ is the coefficient of 
viscoelasticity, $\kappa$ is thermal conductivity, $C_{p}$ is specific heat at constant pressure, $Q_{0}$ denotes the heat source, $Q_{1}^{*}$ denotes the radiation absorption, $q_{r}$ unidirectional radiative heat flux, $K_{c}$ for chemical reaction, $D_{B}$ is Brownian diffusion coefficient, $D_{T}$ thermophoresis diffusion coefficient. The radiative heat flux term by using the Rosseland approximation is given by $q_{r}=-\frac{4 \sigma_{s}}{3 k_{e}} \frac{\partial T^{4}}{\partial y}$.

Where, $\sigma_{s}$ is the Stefan-Boltzmann constant and $k_{e}$ is the mean absorption coefficient, respectively. If temperature differences within the flow are sufficiently small, then the $q_{r}$ can be linearized by expanding $T^{4}$ into the Taylor series about $T_{\infty}$, which after neglecting higher order terms takes the form by $T^{4} \cong 4 T_{\infty}^{3} T-3 T_{\infty}^{4}$. Then the equation (3) becomes,

$$
\begin{aligned}
& \frac{\partial T}{\partial t}+u \frac{\partial T}{\partial x}+v \frac{\partial T}{\partial y}=\frac{\kappa \partial^{2} T}{\rho c_{p} \partial y^{2}}+\frac{v}{c_{p}}\left(\frac{\partial u}{\partial y}\right)^{2}+\frac{Q_{0}}{\rho c_{p}}\left(T-T_{\infty}\right)+\frac{Q_{1}^{*}}{\rho c_{p}}\left(C-C_{\infty}\right) \\
& +\frac{16 \sigma_{s} T_{\infty}^{3}}{3 k_{e} \rho c_{p}} \frac{\partial^{2} T}{\partial y^{2}}+\frac{D_{m} \kappa_{T}}{c_{s} c_{p}} \frac{\partial^{2} C}{\partial y^{2}}+\frac{\sigma^{\prime} B_{0}^{2} u^{2}}{\rho c_{p}}+\Gamma\left\{D_{B}\left(\frac{\partial T}{\partial y} \frac{\partial C}{\partial y}\right)+\frac{D_{T}}{T_{\infty}}\left(\frac{\partial T}{\partial y}\right)^{2}\right\}
\end{aligned}
$$

From the governing equations (1) - (5) under the initial conditions and the boundary conditions will be based on the finite difference method it is required to make the equations dimensionless. For the purpose introducing the following dimensionless quantities:

$X=\frac{x U_{0}}{v}, Y=\frac{y U_{0}}{v}, U=\frac{u}{U_{0}}, V=\frac{v}{U_{0}}, \tau=\frac{t U_{0}^{2}}{v}, \theta=\frac{T-T_{\infty}}{T_{w}-T_{\infty}}, \phi=\frac{C-C_{\infty}}{C_{w}-C_{\infty}}$,

So, $x=\frac{X v}{U_{0}}, y=\frac{Y v}{U_{0}}, u=U U_{0}, t=\frac{\tau v}{U_{0}^{2}}, T=T_{\infty}+\theta\left(T_{w}-T_{\infty}\right)$ and

$C=C_{\infty}+\phi\left(C_{w}-C_{\infty}\right)$, the dimensionless equations are obtained as follows:

\section{Dimensionless Continuity Equation}

$U \frac{\partial U}{\partial X}+V \frac{\partial U}{\partial Y}=0$

\section{Dimensionless Momentum Equation}

$$
\begin{aligned}
& \frac{\partial U}{\partial \tau}+U \frac{\partial U}{\partial X}+V \frac{\partial U}{\partial Y}=\frac{\partial^{2} U}{\partial Y^{2}}-\chi\left[\frac{\partial^{3} U}{\partial \tau \partial Y^{2}}+U \frac{\partial^{3} U}{\partial X \partial Y^{2}}+\frac{\partial U}{\partial X} \frac{\partial^{2} U}{\partial Y^{2}}\right. \\
& \left.-\frac{\partial U}{\partial Y} \frac{\partial^{2} U}{\partial Y^{2}}+V \frac{\partial^{3} U}{\partial Y^{3}}\right]+G_{r} \theta+G_{c} \phi-M U-\frac{1}{D_{a} U}
\end{aligned}
$$

\section{Dimensionless Energy Equation}

$$
\begin{aligned}
& \frac{\partial \theta}{\partial \tau}+\frac{\partial \theta}{\partial Y} U+V \frac{\partial \theta}{\partial Y}=\frac{1}{P_{r}}\left(1+\frac{16 R}{3}\right) \frac{\partial^{2} \theta}{\partial Y^{2}}+Q \theta+Q_{1} \phi \\
& +E_{c}\left(\frac{\partial U}{\partial Y}\right)^{2}+D_{u} \frac{\partial^{2} \phi}{\partial Y^{2}}+E_{c} M U^{2}+N_{b}\left(\frac{\partial \theta}{\partial Y} \frac{\partial C}{\partial Y}\right)+N_{t}\left(\frac{\partial \theta}{\partial Y}\right)^{2}
\end{aligned}
$$

\section{Dimensionless Concentration Equation}

$$
\begin{aligned}
& \frac{\partial \phi}{\partial \tau}+U \frac{\partial \phi}{\partial X}+V \frac{\partial \phi}{\partial Y}=\frac{1}{L_{e}}\left[\frac{\partial^{2} \phi}{\partial Y^{2}}+\left(\frac{N_{t}}{N_{b}}\right) \frac{\partial^{2} \theta}{\partial Y^{2}}\right]-K_{r} \phi^{P} \\
& \tau \leq 0, U=0, V=0, \theta=0, \varphi=0 \text { every where } \\
& \tau>0, U=0, V=0, \theta=0, \varphi=0 \text { at } X=0 \\
& U=1, \theta=1, \varphi=1 \text { at } y=0 \\
& U=0, \theta=0, \varphi=0 \text { at } y \rightarrow \infty
\end{aligned}
$$

Where the obtained physical parameters are given below: magnetic parameter, $M=\frac{\sigma^{\prime} B_{0}^{2} v}{\rho U_{0}^{2}}$, Grashof number, $G_{r}=\frac{g \beta\left(T_{w}-T_{\infty}\right) v}{U_{0}^{3}}$, mass
Grashof number $G_{c}=\frac{g \beta^{*}\left(C_{w}-C_{\infty}\right) v}{U_{0}^{3}}$, Darcy number, $D_{a}=\frac{K^{\prime} U_{0}^{2}}{v^{2}}$, Prandtl number, $P_{r}=\frac{\rho c_{p} v}{\kappa}$, radiation parameter, $R=\frac{\sigma T_{\infty}^{3}}{k_{e} \kappa}$, heat source parameter, $Q=\frac{Q_{0} v}{U_{0}^{2} \rho c_{p}}$, radiation absorption parameter, $Q_{1}=\frac{Q_{1}^{*} v}{U_{0}^{2} \rho c_{p}}$, Eckert number, $E_{c}=\frac{U_{0}^{2}}{c_{p}\left(T_{w}-T_{\infty}\right)}$, Dufour number, $D_{u}=\frac{D_{m} \kappa_{T}}{c_{s} c_{p} v}\left(\frac{C_{w}-C_{\infty}}{T_{w}-T_{\infty}}\right), \quad$ Lewis number, $L_{e}=\frac{v}{D_{m}}$, viscoelastic parameter, $\quad \chi=\frac{\lambda_{0} U_{0}^{2}}{\rho v}, \quad$ Brownian parameter, $N_{b}=\frac{\Gamma D_{B}\left(C_{w}-C_{\infty}\right)}{v}$, thermophoresis parameter $N_{t}=\frac{\Gamma D_{T}}{T_{\infty} v}\left(T_{w}-T_{\infty}\right), \quad$ chemical reaction, $K_{r}=\frac{v K_{c}\left(C_{w}-C_{\infty}\right)^{p-1}}{U_{0}^{2}}$ and Order of chemical reaction $=\mathrm{P}$. Stream function $\psi$ satisfies the continuity equation (6) and is associated with the velocity components in the usual way as,

$U=\frac{\partial \psi}{\partial Y}, V=-\frac{\partial \psi}{\partial X}$

The parameters of technological interest for the present problem are the local skin-friction, the local Nusselt number and the local Sherwood number, which are elucidated below (Rana et al., 2017):

$$
\begin{aligned}
& C_{f}=-\frac{1}{2 \sqrt{2}} G_{r}^{-3 / 4}\left(\frac{\partial U}{\partial Y}\right)_{Y=0} \\
& N_{u}=\frac{1}{\sqrt{2}} G_{r}^{-3 / 4}\left(\frac{\partial \theta}{\partial Y}\right)_{Y=0} \\
& S_{h}=\frac{1}{\sqrt{2}} G_{r}^{-3 / 4}\left(\frac{\partial \phi}{\partial Y}\right)_{Y=0}
\end{aligned}
$$

\section{NUMERICAL SOLUTION}

To solve the governing coupled non-dimensional partial differential equations with the associated initial and boundary conditions. The method of explicit finite difference has been used to solve (6) - (9) subject to the initial and boundary conditions. For this reason, the area within the boundary layer is divided by some perpendicular lines of $Y$ axis, where the normal of the medium is $Y$ - axis as shown in Fig-2. It is assumed that the maximum length of boundary layer $Y_{\max }=20$ as corresponds to $Y \rightarrow \infty$. i.e. $Y$ vary from 0 to 20 and the number of grid spacing in $Y$ directions are $m(=100)$ and $n(=200)$, with the smaller time step $\Delta \tau=0.005$. Using the explicit finite difference approximation, we have,

\section{Continuity Equation}

$$
\frac{U_{i, j}-U_{i, j-1}}{\Delta X}+\frac{V_{i, j}-V_{i, j-1}}{\Delta Y}=0
$$

\section{Momentum Equation}




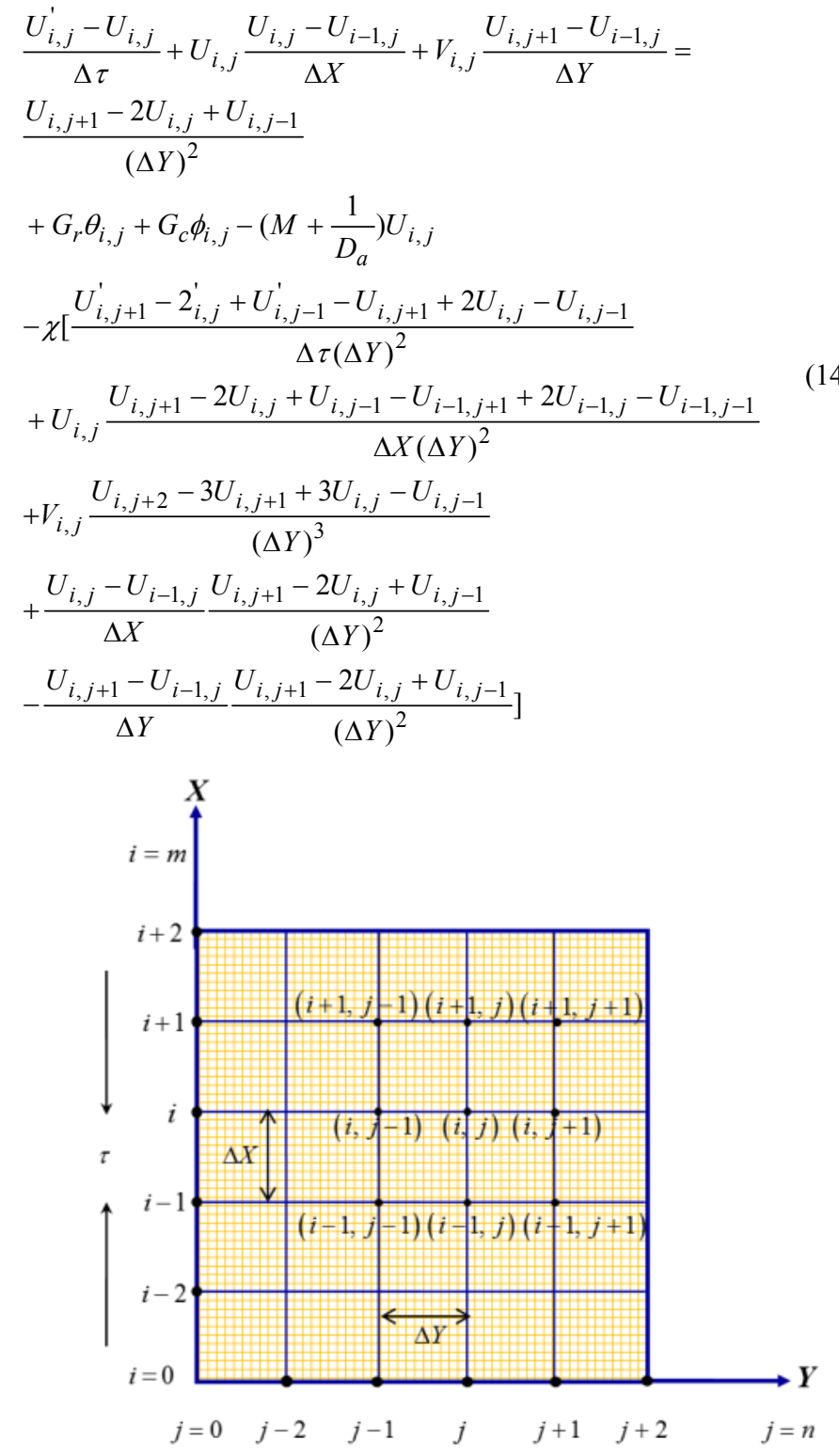

Fig. 2 The finite difference space grid

\section{Energy Equation}

$$
\begin{aligned}
& \frac{\theta_{i, j}^{\prime}-\theta_{i, j}}{\Delta \tau}+U_{i, j} \frac{\theta_{i, j}-\theta_{i-1, j}}{\Delta X}+V_{i, j} \frac{\theta_{i, j+1}-\theta_{i-1, j}}{\Delta Y}= \\
& \frac{1}{P_{r}}\left(1+\frac{16}{3} R\right) \frac{\theta_{i, j+1}-2 \theta_{i, j}+\theta_{i, j-1}}{(\Delta Y)^{2}} \\
& +D_{u} \frac{\phi_{i, j+1}-2 \phi_{i, j}+\phi_{i, j-1}}{(\Delta Y)^{2}}+Q \theta_{i, j}+Q_{1} \phi_{i, j}+E_{c}\left(\frac{U_{i, j+1}-U_{i, j}}{\Delta Y}\right)^{2} \\
& +E_{c} M\left(U_{i, j}\right)^{2}+N_{b}\left(\frac{\theta_{i, j+1}-\theta_{i, j}}{\Delta Y} \cdot \frac{\varphi_{i, j+1}-\varphi_{i, j}}{\Delta Y}\right)+N_{t}\left(\frac{\theta_{i, j+1}-\theta_{i, j}}{\Delta Y}\right)^{2}
\end{aligned}
$$

\section{Concentration Equation}

$$
\begin{aligned}
& \frac{\phi_{i, j}^{\prime}-\phi_{i, j}}{\Delta \tau}+U_{i, j} \frac{\phi_{i, j}-\phi_{i-1, j}}{\Delta X}+V_{i, j} \frac{\phi_{i, j+1}-\phi_{i-1, j}}{\Delta Y}=-K_{r}\left(\phi_{i, j}\right)^{P} \\
& \frac{1}{L_{e}}\left[\frac{\phi_{i, j+1}-2 \phi_{i, j}+\phi_{i, j-1}}{(\Delta Y)^{2}}+\left(\frac{N_{t}}{N_{b}}\right) \frac{\theta_{i, j+1}-2 \theta_{i, j}+\theta_{i, j-1}}{(\Delta Y)^{2}}\right]
\end{aligned}
$$

$U_{i, 0}^{n}=1, \theta_{i, 0}^{n}=1, \phi_{i, 0}^{n}=1$

$U_{i, L}^{n}=0, \theta_{i, L}^{n}=0, \phi_{i, L}^{n}=0$ Where, $L \rightarrow \infty$

\subsection{STABILITY AND CONVERGENCE ANALYSIS OF THE PROBLEM}

Since an explicit finite difference approach is being used therefore the analysis is remained incomplete unless the stability and convergence of the finite difference scheme are discussed. For the constant mesh size the stability criteria of the scheme may be established as follows. The general terms of the Fourier expansion for $U, \theta$ and $\varphi$ at a time arbitrarily called $t=0$ are all $e^{i \alpha X} e^{i \beta Y}$ apart from a constant, where $i=\sqrt{-1}$. A time $t=\tau$, these terms becomes

$$
\left.\begin{array}{l}
U: \psi(\tau) e^{i \alpha X} e^{i \beta Y} \\
\theta: \theta(\tau) e^{i \alpha X} e^{i \beta Y} \\
\varphi: \varphi(\tau) e^{i \alpha X} e^{i \beta Y}
\end{array}\right\}
$$

after a time step these terms convert to

$$
\left.\begin{array}{l}
U: \psi^{\prime}(\tau) e^{i \alpha X} e^{i \beta Y} \\
\theta: \theta^{\prime}(\tau) e^{i \alpha X} e^{i \beta Y} \\
\varphi: \varphi^{\prime}(\tau) e^{i \alpha X} e^{i \beta Y}
\end{array}\right\}
$$

Substituting (17) and (18) to the main (13) -(16) equation we get,

$$
\begin{aligned}
& \psi^{\prime}=\psi(\tau)+\Delta \tau\left[G_{r} \theta+G_{c} \varphi-\left(M+\frac{1}{D_{a}}\right) \psi+\frac{2(\cos \beta \Delta Y-1)}{(\Delta Y)^{2}} \psi\right. \\
& -\frac{U\left(1-e^{i \alpha \Delta X}\right)}{\Delta X} \psi-\frac{V\left(e^{i \beta \Delta Y}-1\right)}{\Delta Y} \psi \\
& -N_{v}\left[\frac{2 \psi^{\prime}(\tau)(\cos \beta \Delta Y-1)-2 \psi(\tau)(\cos \beta \Delta Y-1)}{\Delta \tau(\Delta Y)^{2}}\right. \\
& +U \frac{2 \psi(\tau)(\cos \beta \Delta Y-1)\left(1-e^{-i \alpha \Delta X}\right)}{\Delta X(\Delta Y)^{2}}-\frac{\left(1-e^{-i \alpha \Delta X}\right)}{\Delta X} \cdot \frac{2 \psi(\tau)(\cos \beta \Delta Y-1)}{(\Delta Y)^{2}} \\
& \left.+\frac{\psi(\tau)\left(1-e^{-i \alpha \Delta X}\right)\left(e^{i \beta \Delta Y}-1\right)^{2}}{\Delta Y \cdot \Delta Y \Delta X}+V \frac{\psi(\tau)\left(e^{2 i \beta \Delta Y}-3 e^{i \beta \Delta Y}+3-e^{-i \beta \Delta Y}\right)}{(\Delta Y)^{3}}\right] \\
& \psi^{\prime}=A_{1} \psi+A_{2} \theta+A_{3} \varphi
\end{aligned}
$$

Where,

$$
\begin{aligned}
& A_{1}=1+\Delta \tau \frac{2(\cos \beta \Delta Y-1)}{(\Delta Y)^{2}}-\Delta \tau\left(M+\frac{1}{D_{a}}\right)-\frac{U \Delta \tau\left(1-e^{i \alpha \Delta X}\right)}{\Delta X} \\
& -\frac{V \Delta \tau\left(e^{i \beta \Delta Y}-1\right)}{\Delta Y}-N_{v}\left[\frac{2 U^{2} \Delta \tau(1-\cos \alpha \Delta X)}{(\Delta X)^{2}}+\frac{2 V^{2} \Delta \tau(\cos \beta \Delta Y-1)}{(\Delta Y)^{2}}\right. \\
& \frac{2 \Delta \tau}{(\Delta Y)^{2}}(\cos \beta \Delta Y-1)-\frac{2}{(\Delta Y)^{2}}(\cos \beta \Delta Y-1) \\
& +U \frac{2 \Delta \tau}{\Delta X(\Delta Y)^{2}}(\cos \beta \Delta Y-1)\left(1-e^{-i \alpha \Delta X}\right)-\frac{2 \Delta \tau}{\frac{\left(1-e^{-i \alpha \Delta X}\right)(\cos \beta \Delta Y-1)}{\Delta X(\Delta Y)^{2}}} \\
& \left.\left.+\Delta \tau \frac{\left(1-e^{-i \alpha \Delta X}\right)\left(e^{i \beta \Delta Y}-1\right)^{2}}{\Delta Y \Delta Y \Delta X}+\mathrm{V} \frac{\Delta \tau}{(\Delta Y)^{3}}\left(e^{2 i \beta \Delta Y}-3 e^{i \beta \Delta Y}+3-e^{-i \beta \Delta Y}\right)\right]\right] \\
& A_{2}=\Delta \tau G_{r} \text { and } A_{3}=\Delta \tau G_{c} \text { For temperature equation, } \\
& \theta^{\prime}=\theta+\Delta \tau\left[\frac{1}{P_{r}}\left(1+\frac{16 R}{3}\right) \frac{2 \theta(\cos \beta \Delta Y-1)}{(\Delta Y)^{2}}+D_{u} \frac{2 \varphi(\cos \beta \Delta Y-1)}{(\Delta Y)^{2}}+Q_{1} \varphi\right. \\
& +E_{c} \frac{\left(e^{i \beta \Delta Y}-1\right)}{\Delta Y^{2}} \psi+Q \theta-\frac{U\left(1-e^{i \alpha \Delta X}\right)}{\Delta X} \psi-\frac{V\left(e^{i \beta \Delta Y}-1\right)}{\Delta Y} \psi \\
& \left.+E_{c} M \psi^{2}+N_{b} \theta C\left\{\frac{e^{i \beta \Delta Y}-1}{\Delta Y}\right\}^{2}+N t \theta\left\{\frac{e^{i \beta \Delta Y}-1}{\Delta Y}\right\}^{2}\right]
\end{aligned}
$$

The initial and boundary condition with finite difference scheme as 


$$
\begin{aligned}
& \theta^{\prime}=\theta\left[1+\frac{\Delta \tau}{P_{r}}\left(1+\frac{16 R}{3}\right) \frac{2(\cos \beta \Delta Y-1)}{(\Delta Y)^{2}}+Q \Delta \tau-\frac{U \Delta \tau\left(1-e^{i \alpha \Delta X}\right)}{\Delta X}\right. \\
& \left.-\frac{V \Delta \tau\left(e^{i \beta \Delta Y}-1\right)}{\Delta Y}+N_{t} T \Delta \tau\left\{\frac{e^{i \beta \Delta Y}-1}{\Delta Y}\right\}^{2}+N_{b} C \Delta \tau\left\{\frac{e^{i \beta \Delta Y}-1}{\Delta Y}\right\}^{2}\right] \\
& +\left[Q_{1} \Delta \tau+D_{u} \frac{2 \Delta \tau(\cos \beta \Delta Y-1)}{(\Delta Y)^{2}}\right] \varphi+E_{c} \Delta \tau \frac{U\left(e^{i \beta \Delta Y}-1\right)^{2}}{(\Delta Y)^{2}} \psi+E_{c} \Delta \tau M \psi^{2}
\end{aligned}
$$

For obtaining the stability condition, it should be find out Eigen values of the amplification matrix $\mathrm{T}$, but this study is very difficult since all the elements of $\mathrm{T}$ are different. Hence, the problem requires that the Eckert number $E_{c}$ is assumed to be very small, that is, tends to zero.

Then we get,

$$
\begin{aligned}
& \theta^{\prime}=\theta\left[1+\frac{\Delta \tau}{P_{r}}\left(1+\frac{16 R}{3}\right) \frac{2(\cos \beta \Delta Y-1)}{(\Delta Y)^{2}}+Q \Delta \tau-\frac{U \Delta \tau\left(1-e^{i \alpha \Delta X}\right)}{\Delta X}\right. \\
& \left.-\frac{V \Delta \tau\left(e^{i \beta \Delta Y}-1\right)}{\Delta Y}+N_{t} T \Delta \tau\left\{\frac{e^{i \beta \Delta Y}-1}{\Delta Y}\right\}^{2}++N_{b} C \Delta \tau\left\{\frac{e^{i \beta \Delta Y}-1}{\Delta Y}\right\}^{2}\right] \\
& +\left[Q_{1} \Delta \tau+D_{u} \frac{2 \Delta \tau(\cos \beta \Delta Y-1)}{(\Delta Y)^{2}}\right] \varphi \\
& \theta^{\prime}=A_{4} \theta+A_{5} \varphi
\end{aligned}
$$

Where,

$$
\begin{aligned}
& A_{4}=1+\frac{\Delta \tau}{P_{r}}\left(1+\frac{16 R}{3}\right) \frac{2(\cos \beta \Delta Y-1)}{(\Delta Y)^{2}}+Q \Delta \tau-\frac{U \Delta \tau\left(1-e^{i \alpha \Delta X}\right)}{\Delta X} \\
& -\frac{V \Delta \tau\left(e^{i \beta \Delta Y}-1\right)}{\Delta Y}+N_{t} T \Delta \tau\left\{\frac{e^{i \beta \Delta Y}-1}{\Delta Y}\right\}^{2}++N_{b} C \Delta \tau\left\{\frac{e^{i \beta \Delta Y}-1}{\Delta Y}\right\}^{2}
\end{aligned}
$$

and $A_{5}=Q_{1} \Delta \tau+D_{u} \frac{2 \Delta \tau(\cos \beta \Delta Y-1)}{(\Delta Y)^{2}}$. For the concentration equation,

$$
\begin{aligned}
\varphi^{\prime}= & \varphi+\Delta \tau\left[\frac{1}{L_{e}}\left[\frac{2 \varphi(\cos \beta \Delta Y-1)}{(\Delta Y)^{2}}+\frac{N_{t}}{N_{b}} \frac{2(\cos \beta \Delta Y-1)}{(\Delta Y)^{2}} \theta\right]\right. \\
& \left.-K_{r} \varphi^{P}-\frac{U\left(1-e^{i \alpha \Delta X}\right)}{\Delta X} \varphi-\frac{V\left(e^{i \beta \Delta Y}-1\right)}{\Delta Y} \varphi\right] \\
\varphi^{\prime}= & \varphi\left[1+\frac{2 \Delta \tau(\cos \beta \Delta Y-1)}{S_{c}}-\Delta \tau K_{r}-\frac{U \Delta \tau\left(1-e^{i \alpha \Delta X}\right)}{\Delta X}-\frac{V \Delta \tau\left(e^{i \beta \Delta Y}-1\right)}{\Delta Y}\right] \\
+ & \frac{N_{t}}{N_{b}} \frac{2(\cos \beta \Delta Y-1)}{(\Delta Y)^{2}} \theta
\end{aligned}
$$

$\varphi^{\prime}=A_{6} \varphi+A_{7} \theta$

Where,

$A_{6}=1+\frac{2 \Delta \tau}{L_{e}} \frac{(\cos \beta \Delta Y-1)}{(\Delta Y)^{2}}-\Delta \tau K_{r}-\frac{U \Delta \tau\left(1-e^{i \alpha \Delta X}\right)}{\Delta X}-\frac{V \Delta \tau\left(e^{i \beta \Delta Y}-1\right)}{\Delta Y}$ an

$\mathrm{d} A_{7}=\left(\frac{N_{t}}{N_{b}}\right) \frac{2(\cos \beta \Delta Y-1)}{(\Delta Y)^{2}}$.

Equation (19) -(21) can be expressed in the Matrix form,

$$
\left[\begin{array}{l}
\psi^{\prime} \\
\theta^{\prime} \\
\varphi^{\prime}
\end{array}\right]=\left[\begin{array}{ccc}
A_{1} & A_{2} & A_{3} \\
0 & A_{4} & A_{5} \\
0 & A_{7} & A_{6}
\end{array}\right]\left[\begin{array}{l}
\psi \\
\theta \\
\varphi
\end{array}\right] \text { i.e. } \eta^{\prime}=T^{\prime} \eta
$$

For obtaining the stability condition, Eigen values of the amplification matrix $T^{\prime}$ should be finding out. It is a forth order square matrix. For this explicit finite difference solution, the dimensionless time difference $\Delta \tau$ is very small i.e. tends to zero. Under this condition,

$A_{2} \rightarrow 0, A_{3} \rightarrow 0, A_{5} \rightarrow 0$ and $A_{7} \rightarrow 0$

$\therefore T^{\prime}=\left[\begin{array}{ccc}A_{1} & 0 & 0 \\ 0 & A_{4} & 0 \\ 0 & 0 & A_{6}\end{array}\right]$
After simplification of the matrix $T^{\prime}$ the Eigen values are follows, The Eigen values of the amplification matrix $T^{*}$ are obtained as $A_{1}=\lambda_{1}, A_{4}=\lambda_{2}$ and $A_{6}=\lambda_{3}$. For stability test, each of the Eigen values must not exceeded unity in modulus. Under this consideration, the stability conditions are as follows

$\left|A_{1}\right| \leq 1,\left|A_{4}\right| \leq 1$ and $\left|A_{6}\right| \leq 1$

Let, $a_{1}=\Delta \tau, b_{1}=U \frac{\Delta \tau}{\Delta X}, c_{1}=|-V| \frac{\Delta \tau}{\Delta X}$ and $d_{1}=2 \frac{\Delta \tau}{(\Delta Y)^{2}}$ then,

The coefficient of $\mathrm{a}, \mathrm{b}$ and $\mathrm{c}$ are all non-negative. So the maximum modulus of $A_{1}, A_{4}$ and $A_{6}$ occurs when $\alpha \Delta Y=n \pi$, where $n$ is integer and hence $A_{1}, A_{4}$ and $A_{6}$ are real. The values of $\left|A_{1}\right|,\left|A_{4}\right|$ and $\left|A_{6}\right|$ are greater when $n$ is odd integer, in which case;

$$
\begin{aligned}
& A_{4}=1-2\left[d_{1} \frac{1}{P_{r}}\left(1+\frac{4}{3} R\right)+\frac{a_{1}}{2} Q+b_{1}+c_{1}+2 N_{b} C d_{1}+2 N_{t} T d_{1}\right] \\
& A_{6}=1-2\left[d_{1} \frac{1}{L_{e}}+b_{1}+c_{1}+\frac{a_{1}}{2} \mathrm{~K}_{c}\right]
\end{aligned}
$$

To satisfied allowable values are $A_{1}=-1 A_{4}=-1$ and $A_{6}=-1$. Hence the stability conditions of the methods are,

$U \frac{\Delta \tau}{\Delta X}+V \frac{\Delta \tau}{\Delta X}+\frac{2}{P_{r}}\left(1+\frac{16}{3} R\right) \frac{\Delta \tau}{(\Delta Y)^{2}}-\frac{\Delta \tau Q}{2}+2 N_{b} \frac{\Delta \tau}{(\Delta Y)^{2}}+2 N_{t} \frac{\Delta \tau}{(\Delta Y)^{2}} \leq 1$

and, $U \frac{\Delta \tau}{\Delta X}+V \frac{\Delta \tau}{\Delta X}+\frac{2}{L_{e}} \frac{\Delta \tau}{(\Delta Y)^{2}}+\frac{\Delta \tau K_{r}}{2} \leq 1$.

With initial boundary conditions $U=V=T=C=0$ and for the values of $\Delta \tau=0.005, \Delta X=0.20$ and $\Delta Y=0.25$ then the problem will be converged at $P_{r} \geq 0.253$ and $L_{e} \geq 0.16$. These converge solutions are shown graphically in Figs. 3-25.

\section{RESULTS AND DISCUSSION}

To investigate the physical phenomena of the fluid flow problem from numerical solution, a finite difference solution is obtained by the use of an explicit procedure. The numerical values of non-dimensional velocity, temperature and concentration within the boundary layer for different values of non-dimensional parameter have been computed by a FORTRAN program. For the steady-state solutions, the computations have been carried out up to dimensionless time $\tau=30$.

The interaction of electrically conducting fluids with magnetic fields, through electromagnetic forces called Lorentz forces. Strong magnetic parameter $(M \geq 0.00)$ creates drag force known as Lorentz force and the force impact the fluid velocity to decrease and temperature profiles increase. Which are showing in Fig. 3 and Fig. 4.

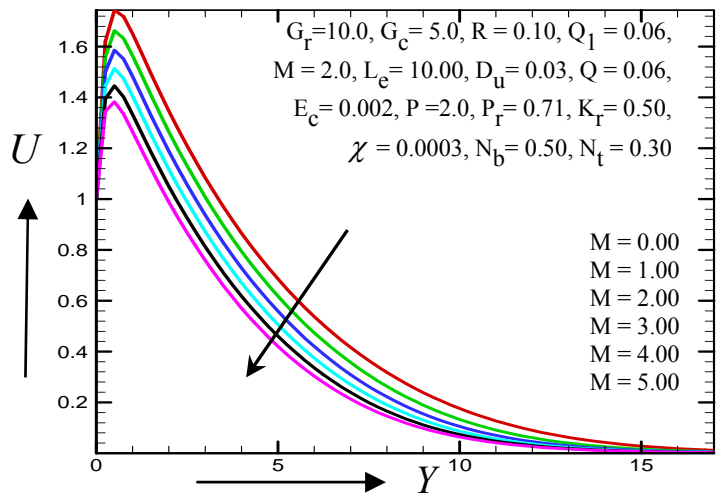

Fig. 3 shows velocity profiles for different values of M 


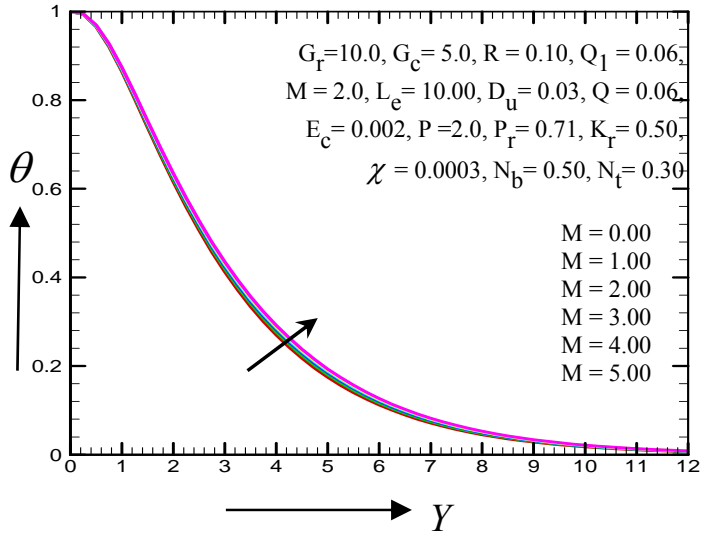

Fig. 4 represents the temperature profiles for different values of $M$

In Fig. 5 describes, the concentration profile decreases with the increase of magnetic parameter $\mathrm{M}$. and thermal boundary layer thickness are enhanced for the larger magnetic parameter. This stronger Lorentz force has an ability to decrease the mass transfer but finally concentration boundary layer thickness increases further from the sheet surface.

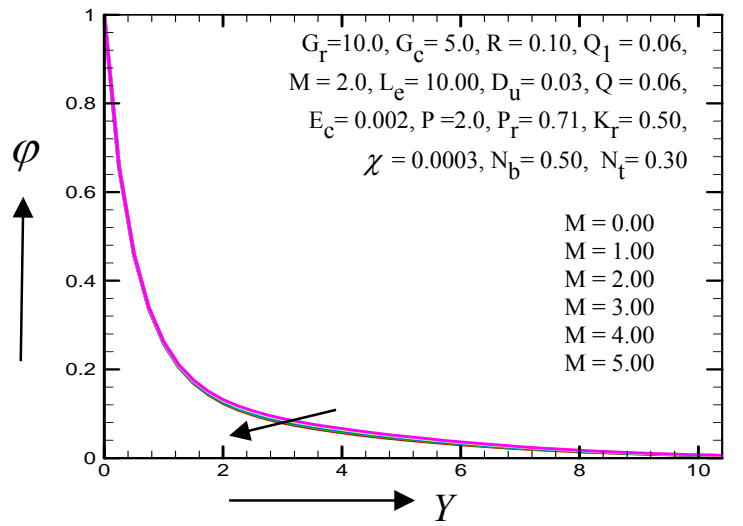

Fig. 5 Concentration profiles for different values of $\mathrm{M}$

From Fig. 6 - Fig. 7 viscoelastic materials have elements of both of these properties and, as such, exhibit time-dependent strain. Whereas elasticity is usually the result of bond stretching along crystallographic planes in an ordered solid, viscosity is the result of the diffusion of atoms or molecules inside an amorphous material. For the increase of viscoelastic parameter from 0.00 to $8 \times 10^{-4}$ the velocity profiles

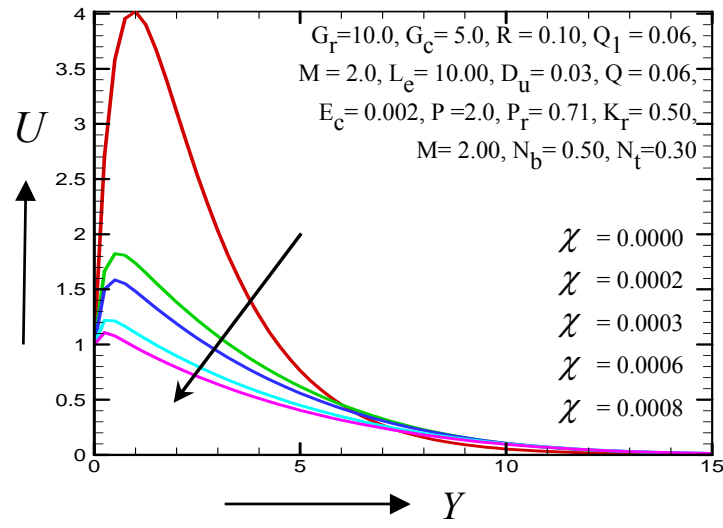

Fig. 6 Velocity profiles for different values of $\chi$

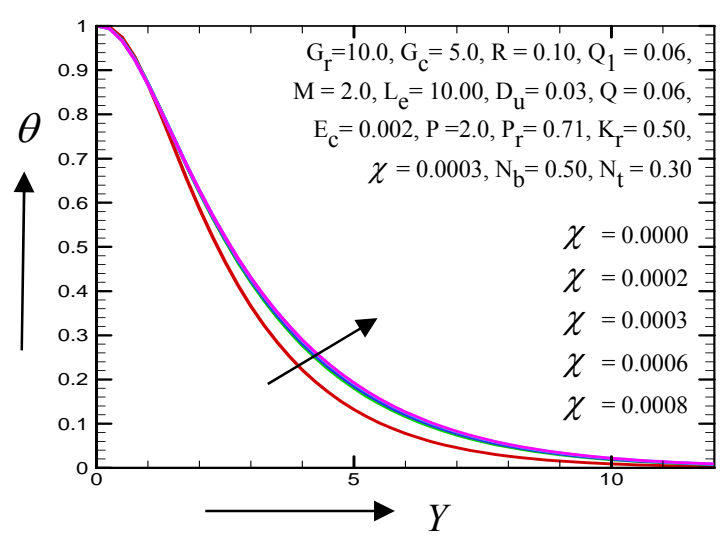

Fig. 7 Temperature profiles for different values of $\chi$

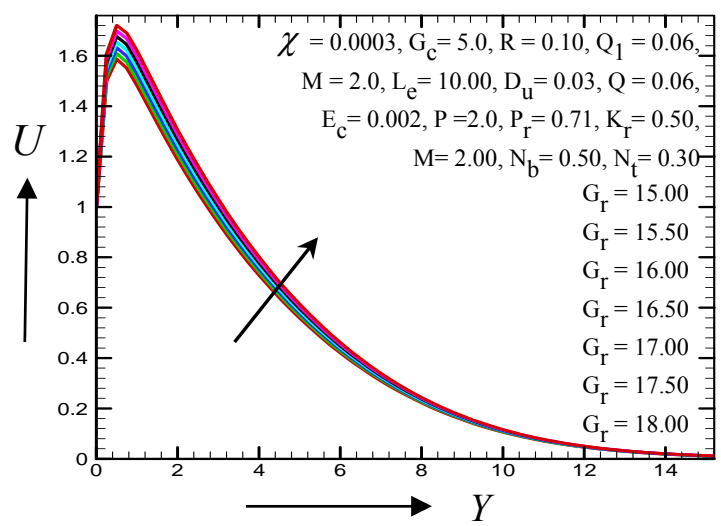

Fig. 8 Velocity profiles for different values of $\mathrm{G}_{\mathrm{r}}$

Table 1. Computations are showing the increase of Nusselt number $\left(N_{u}\right)$ for the increase of $N_{t}$ for $P_{r}=0.71, L_{e}=10.00$ and $\tau=1.20$.

\begin{tabular}{cccccc}
\hline$N_{t}$ & $\begin{array}{c}N_{u} \\
\left(N_{b}=0.10\right)\end{array}$ & $\begin{array}{c}N_{u} \\
\left(N_{b}=0.20\right)\end{array}$ & $\begin{array}{c}N_{u} \\
\left(N_{b}=0.30\right)\end{array}$ & $\begin{array}{c}N_{u} \\
\left(N_{b}=0.40\right)\end{array}$ & $\begin{array}{c}N_{u} \\
\left(N_{b}=0.50\right)\end{array}$ \\
\hline 0.10 & 0.04331 & 0.01959 & 0.00129 & -0.01117 & -0.01778 \\
0.20 & 0.05949 & 0.03146 & 0.00827 & -0.00912 & -0.02035 \\
0.30 & 0.07783 & 0.04614 & 0.01850 & -0.00409 & -0.02036 \\
0.40 & 0.09779 & 0.06303 & 0.03189 & 0.00458 & -0.01733 \\
0.50 & 0.11874 & 0.08210 & 0.04812 & 0.01696 & -0.01019 \\
\hline
\end{tabular}

In Fig. 9 and Fig. 10 illustrate the variations of temperature and concentration profiles for various values of Brownian parameter $\left(N_{b}\right)$.

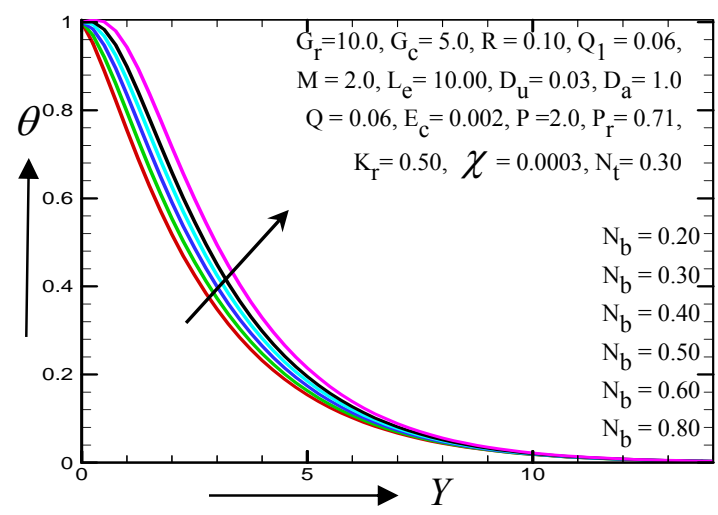

Fig. 9 Temperature profiles for different values of $\mathrm{N}_{b}$ 


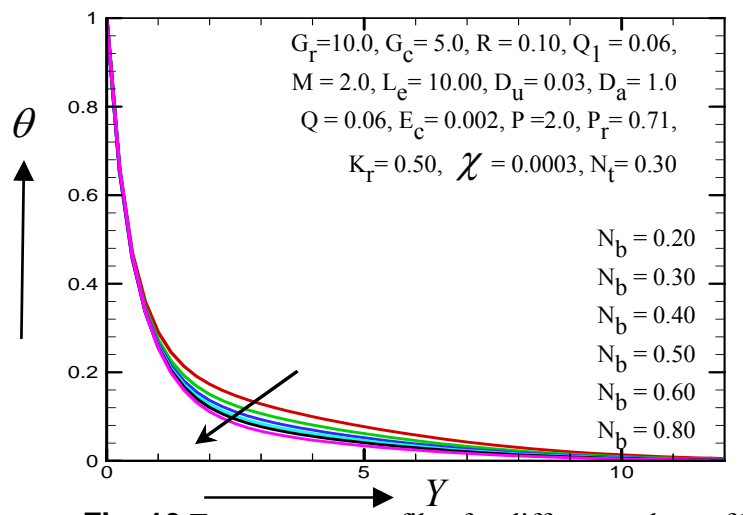

Fig. 10 Temperature profiles for different values of $\mathrm{N}_{b}$

It is found that the increase in the value of $N_{b} \geq 0.20$, the thermal boundary layer increases and the concentration boundary layer reduces. The numerical value obtained from the EFDM simulation for Brownian parameter $\left(N_{b}\right)$ varies from 0.20 to 0.80 . In Fig.11, Temperature profiles decrease for the increase of $N$. From Fig. 12 it can be observed that the concentration profile increases with the increase of thermophoresis parameter $N_{t}$. It is true because $N_{t}$ is directly proportional to thermophoresis diffusion coefficient $D_{T}$ which enhances the mass transfer. Therefore, growing value of $D_{T}$ increases $N t$, which accelerates mass transfer.

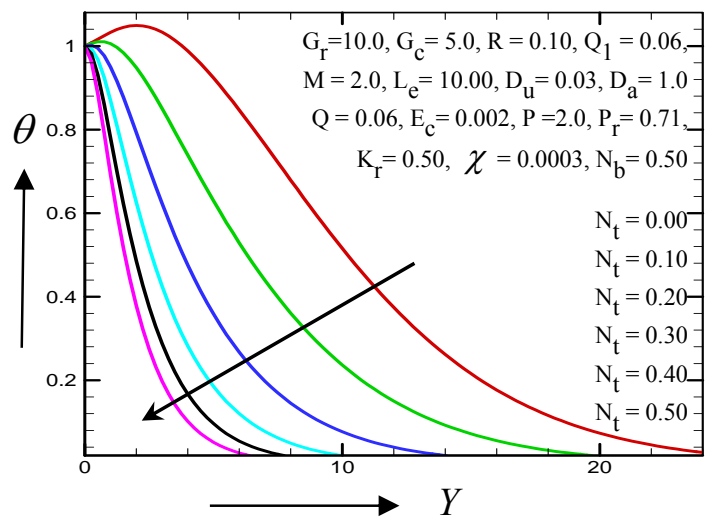

Fig. 11 Temperature profiles for different values of $\mathrm{N}_{\mathrm{t}}$

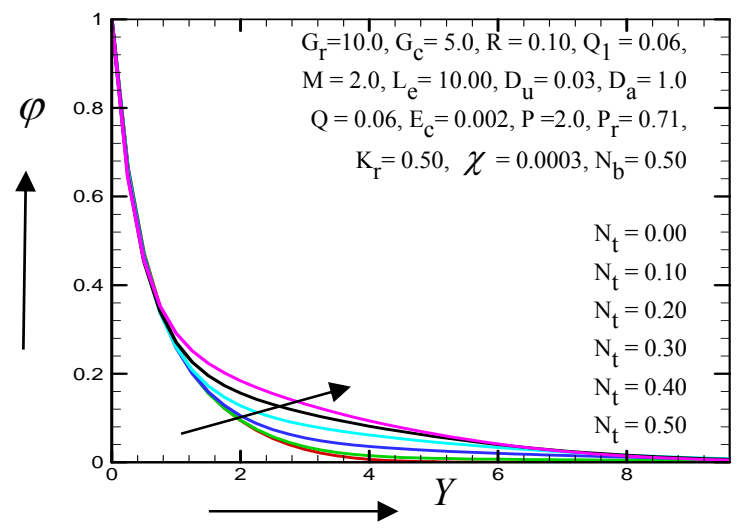

Fig. 12 Concentration profiles for different values of $\mathrm{N}_{t}$

The parameter, $P_{r}$ is the ratio of kinematics viscosity to the thermal diffusivity which is physically very with temperature for example, water $P_{r}=7.0\left(\right.$ At $20^{\circ} \mathrm{C}$ ), Ammonia gases $P_{r}=1.38$ falls more quickly compared to air $P_{r}=0.71$. In addition, $P_{r}<<1$ explains the thermal diffusivity dominates. For the large values of Prandtl number, i.e., $P_{r} \gg 1$, the momentum diffusivity dominates this behavior. In Fig. 13 represents that thermal boundary layer thickness decrease with the increase of Prandtl number. From Fig.14, Sketches the concentration distribution for different values of Lewis number Le. In this figure, it can be seen that concentration profile decreases with the increase of Lewis number Le. This happens because Lewis number is inversely proportional to Brownian diffusion coefficient $D_{B}$, therefore Le increases when $D_{B}$ decreases as a result concentration decrease.

Table 2. Computations are showing the decreased of Sherwood number $\left(S_{h}\right)$ for the increase of $N_{t}$ for $P_{r}=0.71, L_{e}=10.00$ and $\tau=1.20$.

\begin{tabular}{cccccc}
\hline$N_{t}$ & $\begin{array}{l}S_{h} \\
\left(N_{b}=0.10\right)\end{array}$ & $\begin{array}{c}S_{h} \\
\left(N_{b}=0.20\right)\end{array}$ & $\begin{array}{c}S_{h} \\
\left(N_{b}=0.30\right)\end{array}$ & $\begin{array}{l}S_{h} \\
\left(N_{b}=0.40\right)\end{array}$ & $\begin{array}{l}S_{h} \\
\left(N_{b}=0.50\right)\end{array}$ \\
\hline 0.10 & 0.39338 & 0.39693 & 0.39517 & 0.39657 & 0.39557 \\
0.20 & 0.39140 & 0.40458 & 0.40528 & 0.40726 & 0.40591 \\
0.30 & 0.37809 & 0.40840 & 0.41653 & 0.41867 & 0.41589 \\
0.40 & 0.35045 & 0.40428 & 0.42287 & 0.42918 & 0.42865 \\
0.50 & 0.30661 & 0.39420 & 0.42463 & 0.43705 & 0.44249 \\
\hline
\end{tabular}

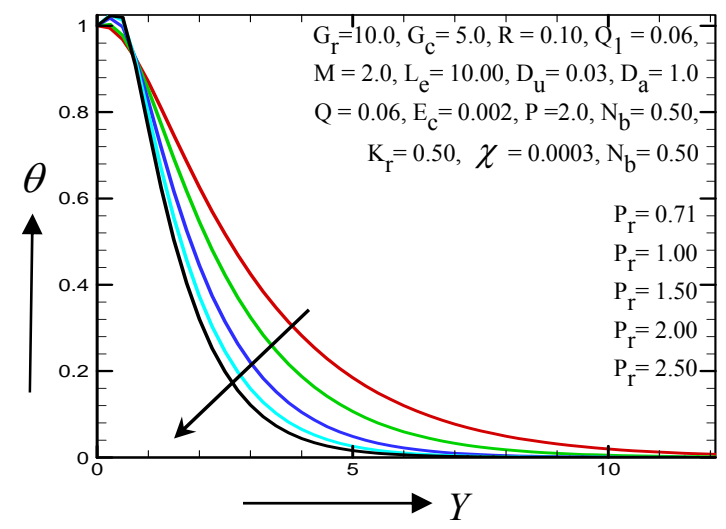

Fig. 13 Temperature profiles for different values of $P_{r}$

Thermal radiation (electromagnetic radiation) could be attributed due to thermal excitation. The temperature could be affected in presence of thermal radiation at moderate temperatures which is significant. Thermal radiation for a medium which contains it inevitably has pressure and density gradients and the treatment requires the use of hydrodynamics.

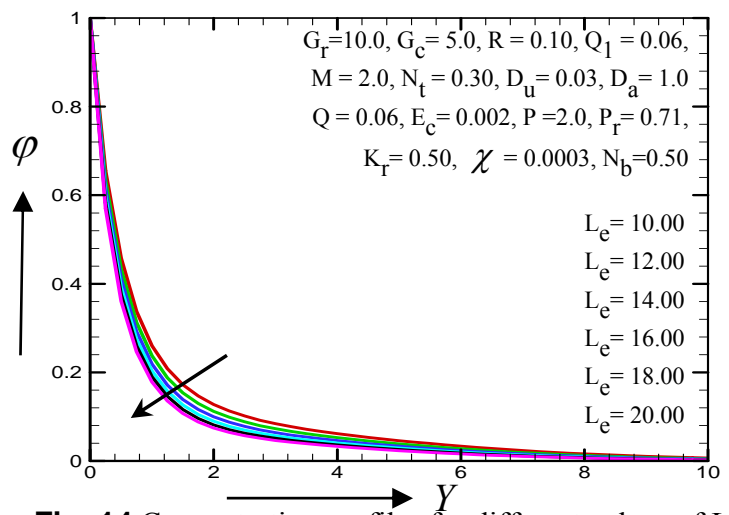

Fig. 14 Concentration profiles for different values of $\mathrm{L}_{\mathrm{e}}$

The consequence is stable for all distances into the boundary layer and validates the advantage of employing thermal radiation in nano-scalematerials dispensation processes. It can be seen that the temperature is in the nano-fluid is significantly intensified for the growing value of 
radiation. Here $\mathrm{R}$ represents the comparative contribution of thermal radiation heat transfer to thermal conduction heat transfer. In Fig.15, describe that the increase of thermal radiation the thermal boundary layer thickness increase and Fig. 16, represents the concentration profiles decrease with the increase of modifies Grashof number.

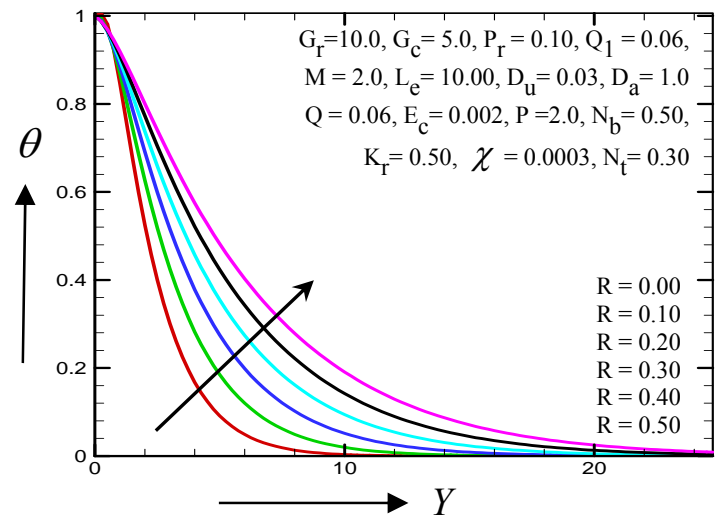

Fig. 15 Temperature profiles for different values of $\mathrm{R}$

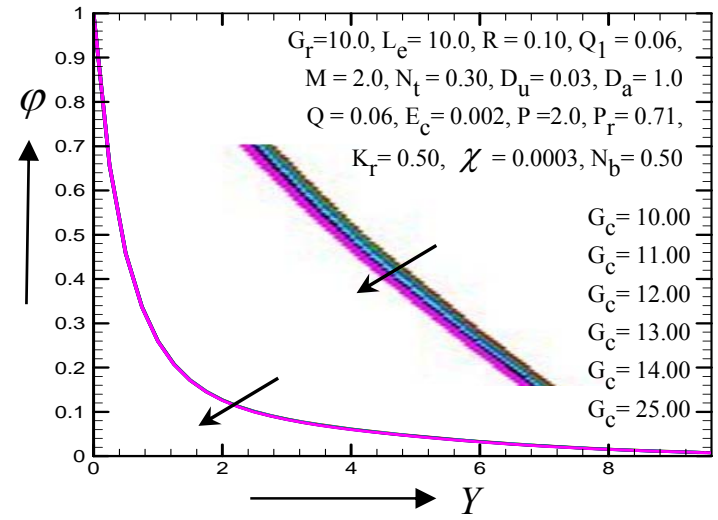

Fig. 16 Concentration profiles for different values of $G_{c}$

The heat generation parameter $Q$ serves to slightly increase the temperature distribution, but the reverse behavior is observed further from the sheet and the flow is accelerated. Therefore, increasing heat generation enhances temperature and increases temperature boundary layer thickness further from the wedge represents in Fig.17. The dimensionless velocity distribution for different values of heat generation parameter Q is illustrated in Fig.18. The nano-particle concentration and concentration boundary layer thickness is decreased with strong heat generation parameter Q closer to the sheet surface but finally concentration boundary layer thickness is increased further from the sheet surface.

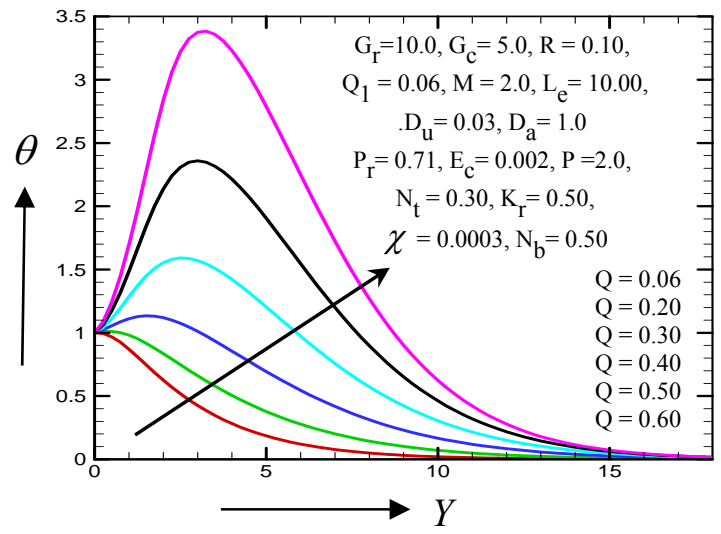

Fig. 17 Temperature profiles for different values of Q

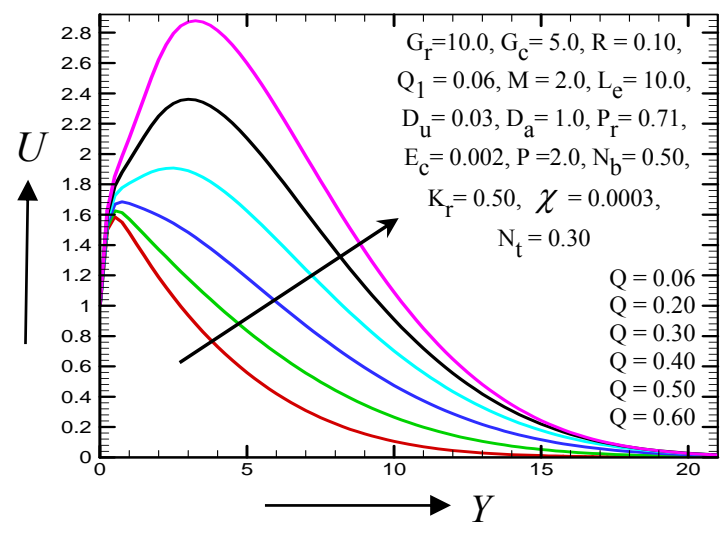

Fig. 18 Velocity profiles for different values of Q

Table. 3. Qualitative comparison of the present results with the previous results Shit et al.

\begin{tabular}{|c|c|c|c|c|c|c|}
\hline \multirow[t]{2}{*}{ Parameter } & \multicolumn{3}{|c|}{$\begin{array}{l}\text { Previous results } \\
\text { given Shit et al. }\end{array}$} & \multicolumn{3}{|c|}{ Present results } \\
\hline & $f^{\prime}$ & $\theta$ & $\varphi$ & $U$ & $\theta$ & $\varphi$ \\
\hline$N_{b}$ & & $\operatorname{Inc}$ & Dec & & Inc & Dec \\
\hline$N_{t}$ & & $\operatorname{Inc}$ & & & $D e c$ & $\operatorname{Inc}$ \\
\hline$L_{e}$ & & & Dec & & & Dec \\
\hline$\chi$ or $K_{1}$ & $\operatorname{Inc}$ & $\mathrm{Dec}$ & & Dec & Inc & \\
\hline$P_{r}$ & & $D e c$ & & & Dec & \\
\hline$G_{r}$ or $\lambda_{t}$ & $\operatorname{Inc}$ & $D e c$ & & $\operatorname{Inc}$ & & \\
\hline$G_{c}$ or $\lambda_{n}$ & & & Dec & & & Dec \\
\hline M & Dec & Inc & Inc & Dec & Inc & $\operatorname{Inc}$ \\
\hline
\end{tabular}

The non-dimensional equation after different transformations has been solved in the present numerical study. Therefore, for this reason, $\mathrm{X}$ and $\mathrm{Y}$ axis are dimensionless which indicates the mash point different from the numerical point of view. In addition, with the stream and isotherms (line view) curves, the difference of boundary layer for different parameters can be defined. The development of streamlines and isotherms are presented in Figs. 19-22. It can be observed that, thermal boundary layer and momentum boundary layer increases due to the increase of viscoelastic parameter, $\chi$.

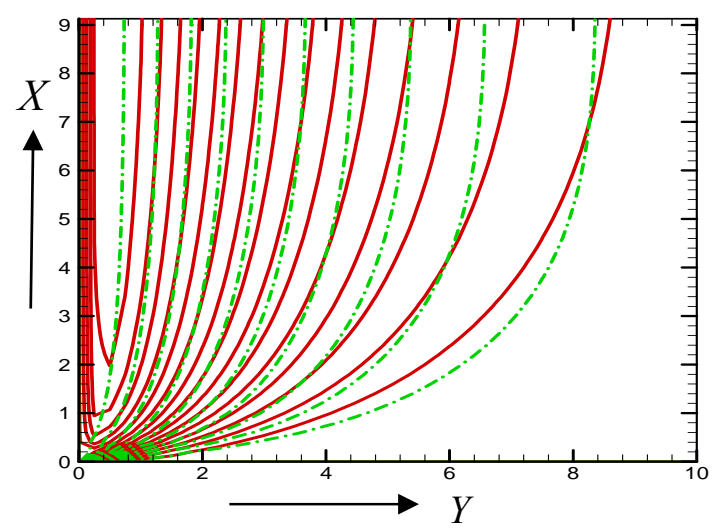

Fig. 19 Illustration of Streamlines for different values line of $\chi$ 


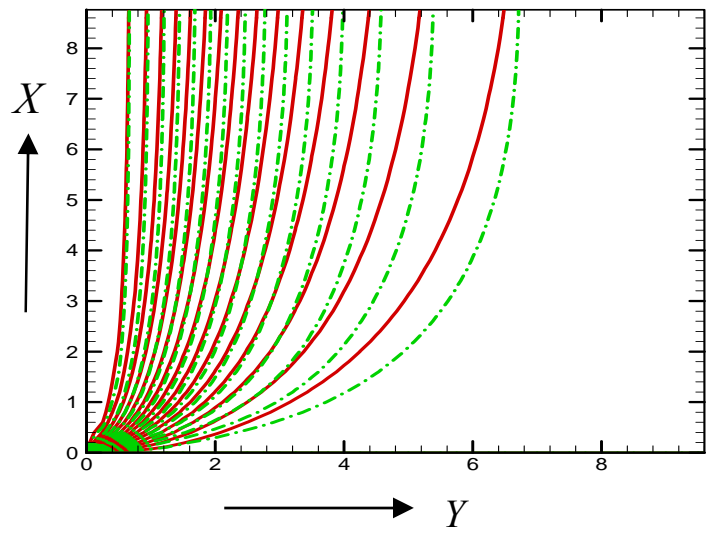

Fig. 20 Illustration of Isotherms line for different values of $\chi$

Furthermore, streamlines profiles can be used to improved visualization of fluid fields. It represents the velocity direction of fluids correspondingly. The streamlines can be obtained by drawing lines tangent to the flags. They are a rather mathematical object. They can be visualized by implanting little flags inside the fluid and observing their orientation. The boundary layer system of change can be shown by an isotherm, where the temperature remains constant $(\Delta T=0)$. An isotherm at $0^{0} \mathrm{C}$ (the freezing point of water) is called the freezing level.

Table. 4. Comparison of $N_{u}$ values with Shit et al. (2016).

\begin{tabular}{llll}
\hline \multicolumn{1}{c}{ Fixed values } & $\begin{array}{c}\text { Parameters } \\
\text { that varying }\end{array}$ & $\begin{array}{c}\text { Shit et al. } \\
(2016) \\
N u\end{array}$ & $\begin{array}{c}\text { Present value } \\
N u\end{array}$ \\
\hline$P r=7, K 1=\chi=0.01$ & $M=0$ & 0.63202 & 0.64184 \\
$N b=0.5, N t=0.3$ & $M=2$ & 0.77514 & 0.78307 \\
$\lambda t$ or $G r=\lambda$ n or $G c=0.5$ & $M=4$ & 0.828622 & 0.84351 \\
$L e=10$ & $M=6$ & 0.864581 & 0.87183 \\
$P r=7, M=2$ & $K 1=\chi=0.0$ & 0.7515194 & 0.75057 \\
$N b=0.5, N t=0.3$ & $K 1=\chi=0.01$ & 0.7751438 & 0.78307 \\
$\lambda t$ or $G r=\lambda$ or $G c=0.5$ & $K 1=\chi=0.05$ & 0.873585 & 0.87185 \\
$L e=10$ & $K 1=\chi=0.1$ & 1.005409 & 1.00313 \\
$P r=7, K 1=0.05$ & $N t=0.0$ & 0.7050363 & 0.71630 \\
$N b=0.5, M=2$ & $N t=0.2$ & 0.8354410 & 0.84352 \\
$L e=10$ & $N t=0.7$ & 0.9433001 & 0.95174 \\
$M=2$ & $L e=20$ & 0.9302426 & 0.92574 \\
\hline
\end{tabular}

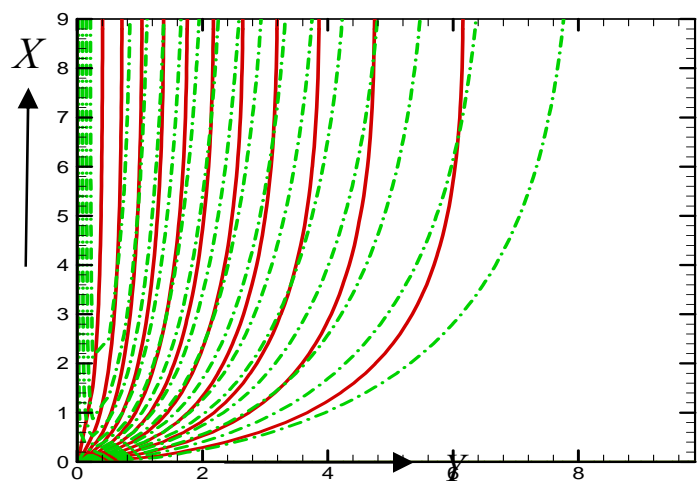

Fig. 21 Illustration of Stream lines for different values line of M

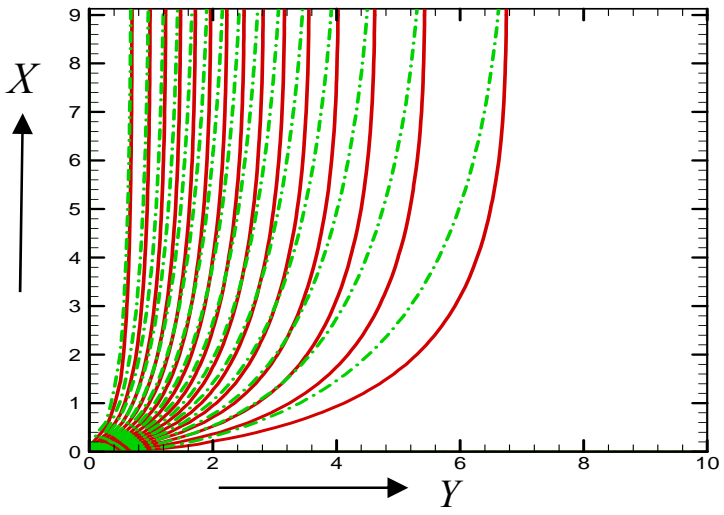

Fig. 22 Illustration of Isotherms line for different values of $M$

In Fig. 21 represent the momentum boundary layer thickness increase but thermal boundary layer thickness decreases for the increase of $\mathrm{M}$.

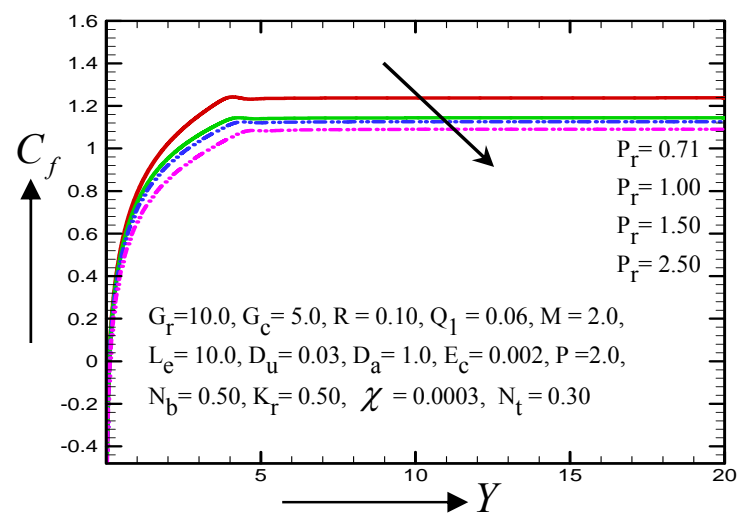

Fig. 23 Illustration of skin friction for different values of $\mathrm{P}_{\mathrm{r}}$

In Fig 23 and Fig 24 represent the skin friction and Nusselt number profiles for Prandtl number differences. Skin number and Nusselt number profile decrease with the increase of Prandtl number.

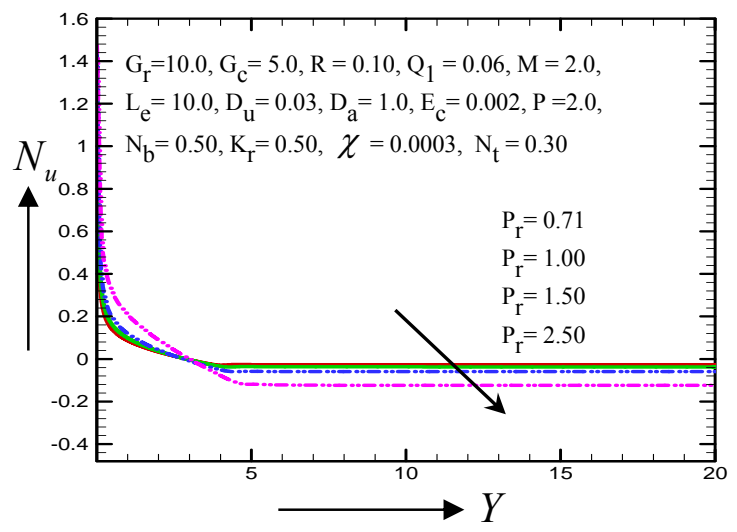

Fig. 24 Illustration of Nusselt number for different values of $P_{r}$

Table 5. Comparison of $N_{u}$ values with $M=Q=\chi=0$ and $P_{r}=L_{e}=10$.

\begin{tabular}{cccccc}
\hline$N_{t}$ & $N_{b}$ & $\begin{array}{c}\text { Khan and } \\
\text { Pop (2010) }\end{array}$ & $\begin{array}{c}\text { Noghrehabadi } \\
\text { et al. (2012) }\end{array}$ & Y & $\begin{array}{c}\text { Present } \\
\text { results }\end{array}$ \\
\hline 0.10 & 0.10 & 0.9524 & 0.9523768 & 0.04 & 0.95703 \\
0.20 & 0.10 & 0.6932 & 0.6931743 & 0.12 & 0.68960 \\
0.30 & 0.10 & 0.5201 & 0.5200790 & 0.17 & 0.51592 \\
0.40 & 0.10 & 0.4026 & 0.4025808 & 0.20 & 0.40827 \\
\hline
\end{tabular}




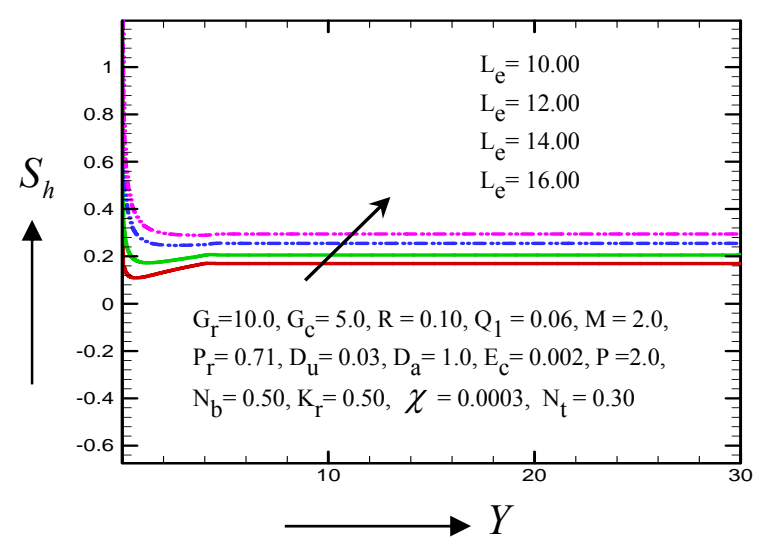

Fig. 25 Illustration of Sherwood number for different values of $\mathrm{L}_{\mathrm{e}}$

Fig 25 represents the Sherwood number profiles with the difference of $\mathrm{L}_{\mathrm{e}}$. Sherwood number profiles increase with the increase of $\mathrm{L}_{\mathrm{e}}$.

\section{CONCLUSIONS}

The Numerical solutions for viscoelastic fluid with nano - particle towards a moving semi-infinite porous stretching sheet with thermal radiation, heat source, chemical reaction, and mass diffusion is analysed. The results are presented graphically with various parameters. Form the graphical representation, we have the following observations:

- $\quad$ Temperature and concentration profiles increase but velocity profiles decrease with the increase of magnetic parameter.

- For the increase of viscoelastic parameter, the velocity profile decreases and temperature profiles increase.

- Velocity profiles increase with the increase of Grashof number and concentration profiles decrease for modified Grashof number.

- Due to increase of Brownian parameter temperature profiles increase and concentration profiles decrease.

- For the increase of thermophoresis parameter temperature profiles decrease and concentration profiles increase.

- Temperature, skin friction and Nusselt number profiles decrease for increase of Prandtl number and concentration curves decrease for Lewis number. Sherwood number profiles increase with the increase of Lewis number.

- Temperature profiles increase for increase of thermal radiation and heat generation, also for velocity.

- For the increase of viscoelastic parameter, the thermal and concentric boundary layer increases.

- Increase of magnetic parameter the thermal and concentric boundary layer decreases.

\section{ACKNOWLEDGEMENTS}

The authors wish to express their very sincerely thanks to the reviewers for their valuable comments and suggestions.

\section{NOMENCLATURE}

$B$ magnetic component, $\left(\mathrm{Wb} \mathrm{m}^{-2}\right)$

$C_{f} \quad$ skin-friction, (-)

$C_{p} \quad$ specific heat at constant pressure, $\left(\mathrm{J} \mathrm{kg}^{-1} \mathrm{~K}^{-1}\right)$

$D_{B} \quad$ Brownian diffusion coefficient, (-)

$D_{u} \quad$ Dufour number, (-)

$E_{c} \quad$ Eckert number, (-)

$G_{r} \quad$ Grashof number, (-)
$G_{c} \quad$ modified Grashof number, (-)

$k_{e} \quad$ mean absorption coefficient

$L_{e} \quad$ Lewis number, (-)

$N_{b} \quad$ Brownian parameter, (-)

$N_{t} \quad$ thermophoresis parameter, (-)

$N_{u} \quad$ local Nusselt number, (-)

$\chi \quad$ Viscoelastic parameter

$P_{r} \quad$ Prandtl number, (-)

$q_{r} \quad$ unidirectional radiative heat flux, $(\mathrm{kg} \mathrm{m}-2)$

$Q_{1}{ }^{*}$ radiation absorption, (-)

$Q$ 。 heat absorption quantity, (-)

$S_{h} \quad$ Sherwood number, (-)

$\mathrm{T} \quad$ Fluid temperature, $(\mathrm{K})$

$\mathrm{T}_{\mathrm{W}} \quad$ Temperature at the plate surface, $(\mathrm{K})$

$T_{\infty} \quad$ ambient temperature as y tends to infinity, $(\mathrm{K})$

$U_{\circ} \quad$ uniform velocity

$u, v$ velocity components

$x, y$ Cartesian co-ordinates

Greek symbols

$\rho$ density of the fluid, $\left(\mathrm{kg} \mathrm{m}^{-3}\right)$

$m$ dynamic viscosities

$v \quad$ kinematic viscosity, $\left(\mathrm{m}^{2} \mathrm{~s}^{-1}\right)$

$\beta \quad$ thermal expansion co-efficient

$\beta^{*} \quad$ concentration expansion co-efficient

$\kappa$ thermal conductivity, $(\mathrm{Wm}-1 \mathrm{~K}-1)$

$\sigma_{s} \quad$ Stefan-Boltzmann constant, $5.6697 \times 10-8(\mathrm{~W} / \mathrm{m} 2 \mathrm{~K} 4)$

Abbreviations

DRA Duan-Rach Approach

EFDM explicit finite difference method

ODE ordinary differential equation

PDE partial differential equations

SCA stability and convergence analysis

\section{REFERENCES}

Biswas, P., Arifuzzaman, S.M., Karim, I. and Khan, M.S., 2017, "Impacts of Magnetic Field and Radiation Absorption on Mixed Convective Jeffrey Nano Fluid Flow over a Vertical Stretching Sheet with Stability and Convergence Analysis," Journal of nanofluid, 6(6), 1082-1095.

https://doi.org/10.1166/jon.2017.1407

Bég, O.A., Khan, M.S., Karim, I., Alam, M.M., Ferdows, M., 2014, "Explicit Numerical Study of Unsteady Hydromagnetic Mixed Convective Nanofluid Flow from an Exponentially Stretching Sheet in Porous Media," Applied Nanoscience, 4, 943-957.

http://dx.doi.org/10.1007/s13204-013-0275-0

Dogonchi, A. S., Divsalar, K. and Ganji, D.D., 2016, "Flow and Heat Transfer of MHD Nanofluid Between Parallel Plates in the Presence of Thermal Radiation," Computer Methods in Applied Mechanics and Engineering, 310, 58-76.

https://doi.org/10.1016/j.cma.2016.07.003

Dogonchi, A.S., Alizadeh, M. and Ganji, D.D., 2017, "Investigation of MHD Go-water Nanofluid Flow and Heat Transfer in a Porous Channel In The Presence Of Thermal Radiation Effect," Advanced Powder Technology, 28(7), 1815-1825.

https://doi.org/10.1016/j.apt.2017.04.022

Dogonchi, A.S., Ganji, D.D., 2016, "Investigation of MHD Nanofluid Flow and Heat Transfer in a Stretching/shrinking Convergent/divergent 
Channel Considering Thermal Radiation," Journal of Molecular Liquids, 220, 592-603.

http://dx.doi.org/10.1016/j.molliq.2016.05.022

Dogonchi, A.S., Ganji, D.D., 2016, "Thermal Radiation Effect on the Nano-fluid Buoyancy Flow and Heat Transfer over a Stretching Sheet Considering Brownian Motion," Journal of Molecular Liquids, 223, 521-527.

https://doi.org/10.1016/j.molliq.2016.08.090

Dogonchi, A.S., Ganji, D.D.,2016, "Study of Nanofluid Flow and Heat Transfer between Non-parallel Stretching Walls Considering Brownian Motion," Journal of the Taiwan Institute of Chemical Engineers, 69, 113.

https://doi.org/10.1016/j.jtice.2016.09.029

Dogonchi, A.S., Ganji, D.D., 2015, "Investigation of Heat Transfer for Cooling Turbine Disks with a Non-Newtonian Fluid Flow Using DRA," Case Studies in Thermal Engineering, 6, 40-51. https://doi.org/10.1016/j.csite.2015.06.002

Das, S., Jana, R.N. and Makinde, O.D., 2015, "Magnetohydrodynamic Mixed Convective Slip Flow over an Inclined Porous Plate with Viscous Dissipation and Joule Heating," Alexandria Engineering Journal, 54(2), 251-261.

http://dx.doi.org/10.1016/j.aej.2015.03.003

Fetecau, C. and Zierep, J., 2003, "The Rayleigh-Stokes-Problem for a Maxwell Fluid," Z Angew Math Phys (ZAMP), 54, 1086-1093.

http://dx.doi.org/10.1007/s00033-008-8055-5

Ferdows, M., Khan, M.S., Bég, O.A., Alam, M.M., 2013, "Numerical Study of Transient Magnetohydrodynamic Radiative Free Convection Nanofluid Flow from A Stretching Permeable Surface," Journal of Process Mechanical Engineering, 228, 81-196.

http://dx.doi.org/10.1177/0954408913493406

Hsiao, K.L., 2017, “Combined Electrical MHD Heat Transfer Thermal Extrusion System Using Maxwell Fluid with Radiative and Viscous Dissipation Effects," Applied Thermal Engineering, 112, 1281-1288. http://dx.doi.org/10.1016/j.applthermaleng.2016.08.208

Ibáñez, G., López, A., Pantoja, J. and Moreira, J., 2016, "Entropy Generation Analysis of a Nanofluid Flow In MHD Porous Microchannel with Hydrodynamic Slip and Thermal Radiation," International Journal of Heat and Mass Transfer, 100, 89-97.

http://dx.doi.org/10.1016/j.ijheatmasstransfer.2016.10.126

Khan, N., Mahmood, T., Sajid, M. and Hashmi, M.S., 2016, "Heat and Mass Transfer on MHD Mixed Convection Axisymmetric Chemically Reactive Flow of Maxwell Fluid Driven by Exothermal and Isothermal Stretching Disks," International Journal of Heat and Mass Transfer, 92, 1090-1105.

http://dx.doi.org/10.1016/j.ijheatmasstransfer.2015.09.001

Khan, W. A. and Pop, I., 2010, "Boundary-Layer Flow of a Nanofluid Past a Stretching Sheet," International Journal of Heat and Mass Transfer, 53, (11-12), 2477-2483. https://doi.org/10.1016/i.ijheatmasstransfer.2010.01.032

Khan, M.S., Karim, I., Ali, L.E., Islam, A., 2012, “Unsteady MHD Free Convection Boundary-layer Flow of a Nanofluid along a Stretching Sheet with Thermal Radiation and Viscous Dissipation Effects," International Nano Letters, 2, 1-9.

http://dx.doi.org/10.1186\%2F2228-5326-2-24

Mohamed, R.A. and Abo-Dahab, S.M., 2009, "Influence of Chemical Reaction and Thermal Radiation on the Heat and Mass Transfer in MHD Micropolar Flow over a Vertical Moving Porous Plate in a Porous Medium with Heat Generation," International Journal of Thermal Sciences, 48(9), 1800-1813.

http://dx.doi.org/10.1016/j.ijthermalsci.2009.01.019

Murthy, M.V.R., Raju, R.S. and Rao, J.A., 2015, "Heat and Mass Transfer Effects on MHD Natural Convective Flow Past an Infinite Vertical Porous Plate with Thermal Radiation and Hall Current," Procedia Engineering, 127, 1330-1337. https://doi.org/10.1016/j.proeng.2015.11.491

Noghrehabadi, Pourrajab, R. and Ghalambaz, M., 2012, "Effect of Partial Slip Boundary Condition on the Flow and Heat Transfer of Nanofluids Past Stretching Sheet Prescribed Constant Wall Temperature," International Journal of Thermal Sciences, 54, 253-261. http://dx.doi.org/10.1016/j.ijthermalsci.2011.11.017

Nandy, S.K. and Mahapatra, T.R., 2013, "Effects of Slip and Heat Generation/absorption On MHD Stagnation Flow of Nanofluid Past a Stretching/shrinking Surface with Convective Boundary Conditions," International Journal of Heat and Mass Transfer, 64, 1091-1100. http://dx.doi.org/10.1016/j.ijheatmasstransfer.2013.05.040

Ramachandra P. V., Vasu, B. and Bég, O.A., 2011, "Thermo-diffusion and Diffusion-thermo Effects on MHD Free Convection Flow Past a Vertical Porous Plate Embedded in a Non-Darian Porous Medium," Chemical Engineering Journal, 173(2), 598-606.

http://dx.doi.org/10.1016/j.cej.2011.08.009

Ramesh, G.K., Gireesha, B.J., Hayat, T. and Alsaedi, A., 2016, "Stagnation Point Flow of Maxwell Fluid towards A Permeable Surface in the Presence of Nanoparticles," Alexandria Engineering Journal, 55, $857-865$.

http://dx.doi.org/10.1016/j.aej.2016.02.007

Rana, B.M.J., Ahmed, R., Ahmmed, S.F., 2017, "Thermal Radiation and Mass Transfer Effects on Unsteady MHD Free Convection Flow Past a Vertical Oscillating Plate," AIP Conference Proceedings, 1851, 020014.

http://dx.doi.org/10.1063/1.4984643

Shit, G.C., Haldar, R. and Ghosh, S.K., 2016, "Convective Heat Transfer and MHD Viscoelastic Nanofluid Flow Induced by a Stretching Sheet," International Journal of Applied and Computational Mathematics, 2(59), 3-608.

http://dx.doi.org/10.1007/s40819-015-0080-4 
Frontiers in Heat and Mass Transfer (FHMT), 9, 5 (2017)

Global Digital Central DOI: 10.5098/hmt.9.5

ISSN: 2151-8629 